DOI 10. 18307/2021. 0525

(C) 2021 by Journal of Lake Sciences

\title{
藏南冰前湖枪勇错近百年沉积速率变化及冰川进退反演
}

\author{
张 润 ${ }^{1,2}$, 金章东 $^{1,3 * *}$, 张 飞 ${ }^{1,3}$, 张小龙 ${ }^{4}$, 李良波 ${ }^{1,2}$,徐 阳 ${ }^{1,2}$, 徐柏青 4,5 \\ (1: 中国科学院地球环境研究所,黄土与第四纪地质国家重点实验室,西安 710061) \\ (2: 中国科学院大学, 北京 100049) \\ (3: 中国科学院第四纪科学与全球变化卓越创新中心,西安 710061) \\ (4: 中国科学院青藏高原研究所, 青藏高原环境变化与地表过程重点实验室, 北京 100101) \\ (5: 中国科学院青藏高原地球科学卓越创新中心, 北京 100101)
}

\begin{abstract}
摘 要: 青藏高原上分布着大量的大陆性冰川, 其对区域及全球气候变化响应极其敏感. 工业革命以来, 随着全球升温速 率加快 (特别是北半球), 青藏高原部分地区的冰川在近百年显著退缩. 冰前湖沉积物是最直接的冰川变化记录载体之 一, 但其沉积速率如何响应冰川及气候变化, 能否反演冰川进退过程却知之甚少. 本文依据 ${ }^{210} \mathrm{~Pb}$ 和 ${ }^{137} \mathrm{Cs}$ 限定藏南冰前湖 枪勇错 QY5 沉积岩芯的年龄, 计算出不同深度沉积物的沉积速率, 且与前人 (QY-3) 的沉积速率进行对比, 揭示了近百年 来枪勇错流域冰川变化历史及其与气温之间的关系. 结果表明, 枪勇错 QY5 近百年来的平均沉积速率为 $0.21 \mathrm{~cm} / \mathrm{a}$, 比湖 心 ( QY-3) 快 2 倍左右, 但两者的变化基本同步, 高沉积速率对应温度上升期, 是冰川退缩的直接响应: ( 1) 1900-1960 年, 枪勇错沉积速率整体增加且变幅较大, 与 1890-1950 年之间西藏温度波动式升高相对应, 反映枪勇冰川总体处于退 缩状态; (2) 1960-1985 年, 沉积速率低且变幅较小, 同期气温下降,枪勇冰川退缩程度相对较低且保持平稳; (3) 1985 年 以来, 枪勇错沉积速率呈上升趋势, 是全球增暖下冰川显著退缩的直接响应. 在短时间尺度内冰前湖沉积速率所揭示的 枪勇冰川变化主要受控于温度, 降水量对冰川变化的影响较小, 但冰川对温度变化的响应滞后 $5 \sim 10 \mathrm{a}$. 由于全球变暖和 冰川对温度响应的滞后,在未来几十年高原冰川的融化速率可能会加快,亚洲水塔将面临着新的挑战.
\end{abstract}

关键词: 沉积速率; ${ }^{210} \mathrm{~Pb}$ 和 ${ }^{137} \mathrm{Cs}$ 测年; 冰川变化; 全球变暖;冰前湖;枪勇错

\section{Sedimentation rate variations of the proglacial lake ( Qiangyong Co) and its implications for glacial fluctuations over the past century, southern Tibet, China*}

Zhang Run ${ }^{1,2}$, Jin Zhangdong ${ }^{1,3 * *}$, Zhang Fei ${ }^{1,3}$, Zhang Xiaolong ${ }^{4}$, Li Liangbo ${ }^{1,2}$, Xu Yang ${ }^{1,2} \&$ Xu Baiqing ${ }^{4,5}$

(1: State Key Laboratory of Loess and Quaternary Geology, Institute of Earth Environment, Chinese Academy of Sciences, Xi'an 710061, P.R.China)

(2: University of Chinese Academy of Sciences, Beijing 100049, P.R.China)

(3: CAS Center for Excellence in Quaternary Science and Global Change, Xi'an 710061, P.R. China)

(4: Key Laboratory of Tibetan Environment Changes and Land Surface Processes, Institute of Tibetan Plateau Research, Chinese Academy of Sciences, Beijing 100101, P.R.China)

(5: CAS Center for Excellence in Tibetan Plateau Earth Sciences, Chinese Academy of Sciences, Beijing 100101, P.R.China)

Abstract: Continental glaciers on the Tibetan Plateau are sensitive to regional and global climate change. Since the industrial revolution, with the acceleration of global warming (especially in the Northern Hemisphere), glaciers in most parts of the Tibetan Plateau have shrunk significantly over the past century. The sediments in proglacial lakes are one of the direct record carriers of glacial fluctuations, but little is known about how their sedimentation rate (SR) responds to glacier and climate changes, particularly un-

* 2020-10-14 收稿;2021-02-05 收修改稿.

中国科学院战略性先导科技专项 (XDA2007010202, XDB40020100) 资助.

** 通信作者;E-mail: zhdjin@ ieecas.cn. 
der the background of global warming. In this study, the ${ }^{210} \mathrm{~Pb}$ and ${ }^{137} \mathrm{Cs}$ activities were used to constrain the age of a core (QY5) from Qiangyong Co in southern Tibet and to calculate the SRs of the core sediments at different depths. By comparing the SRs of the core ( QY5) with those of the QY-3 core from central Qiangyong Co, the history of glacial fluctuations and its relationship with air temperature during the last century were revealed. The results show that the average SR of upstream of Qiangyong Co (QY5) is $0.21 \mathrm{~cm} / \mathrm{a}$, about double of the centre of the lake (QY-3), but with the same patterns. High SRs are corresponded to warm temperatures, as a direct response to the glacial retreat within the Qiangyong catchment: (1) from 1900s to 1960s, the SR of Qiangyong Co increased and fluctuated greatly as a result of the glacial retreat, corresponding to increased temperature in Tibet between 1890s and 1950s; (2) during 1960s-1985 when temperature decreased, the SR was low and stable, indicating stable Qiangyong glacier; (3) since 1985, the SR in Qiangyong Co increased gradually, as a direct response to glacier retreat under the acceleration of the global warming. Over a short time scale, the change of the Qiangyong glacier revealed by the SR in the proglacial lake is mainly controlled by air temperature, rather than by precipitation. However, there is a 5 to 10 years delay of glacier retreat to increased temperature. Due to global warming and the delayed response of glacier retreat to temperature, the melting rate of the Qiangyong glacier may accelerate in the next decades, and the Asian water tower will face a new challenge.

Keywords: Sedimentation rate; ${ }^{210} \mathrm{~Pb}$ and ${ }^{137} \mathrm{Cs}$ dating; glacial fluctuations; global warming; proglacial lake; Qiangyong Co

湖泊作为流域地表风化物质的最终聚集地,其沉积具有分辨率高、沉积记录连续等优点, 对湖泊沉积物 进行研究可以揭示区域气候及环境变迁历史 ${ }^{[1-3]}$. 沉积速率作为湖泊沉积学研究的手段之一, 是指在重力作 用下的沉积物和不同理化性质的流体与外界环境相互作用并在单位时间内堆积的沉积物的厚度 ${ }^{[4]}$. 沉积速 率不仅可以反映沉积过程, 也可以定量确定外源或内源物质的沉积环境 ${ }^{[5]}$. 不同时间尺度沉积速率的变化 模式可以反映湖泊不同的演化特征, 长时间尺度沉积速率反映地质历史时期湖泊的形成演化过程, 短时间 尺度沉积速率则体现了近现代湖泊的水动力及与区域物质的交换过程 ${ }^{[6]}$.

工业革命以来, 全球地表升温速率 (特别是北半球) 已达到过去 $2000 \mathrm{a}$ 来的最大值 ${ }^{[7-8]}$. 在全球气候变 暖背景之下, 喜马拉雅地区的冰川明显退缩 ${ }^{[9]}$, 冰川物质强烈亏损对冰川补给湖泊造成了巨大影响 ${ }^{[10]}$. 冰 前湖的水源主要由冰川融水补给, 其沉积物作为冰川变化的忠实记录者, 保存着丰富的地质信息, 对冰川及 气候变化均有良好响应 ${ }^{[11-17]}$. 近百年来青藏高原冰川剧烈波动, 前人利用冰前湖沉积的粒度、磁学、元素地 球化学和狍粉等指标研究冰川变化,但是利用沉积速率来揭示冰川变化的研究鲜有报道.

对湖泊沉积物进行精确定年是重建区域环境变化历史的前提和关键所在. ${ }^{210} \mathrm{~Pb}$ 和 ${ }^{137} \mathrm{Cs}$ 定年方法具有 分辨率高、年代结果可靠等优点, 这两种方法在年代结果上可以相互印证, 已被广泛地运用到湖泊沉积物年 龄的研究中 ${ }^{[2,5,18-23]}$. 本研究通过 ${ }^{210} \mathrm{~Pb}$ 和 ${ }^{137} \mathrm{Cs}$ 的活度限定藏南冰前湖枪勇错沉积物的年代, 计算出近百年来 不同时段枪勇错沉积物的沉积速率, 进而利用沉积速率揭示工业革命以来枪勇冰川的变化历史, 并探讨在 全球变暖的气候背景下温度变化对枪勇冰川变化的影响.

\section{1 研究区概况}

枪勇错 $\left(28^{\circ} 53^{\prime} 20.40^{\prime \prime} \sim 28^{\circ} 53^{\prime} 31.56^{\prime \prime} \mathrm{N}, 90^{\circ} 13^{\prime} 26.04^{\prime \prime} \sim 90^{\circ} 13^{\prime} 36.48^{\prime \prime} \mathrm{E}\right.$, 湖面海拔 $4875 \mathrm{~m}$ ) 位于青藏高原南 部、喜马拉雅山北坡、雅鲁藏布江南岸(图 1a,b), 是一个由冰川后退遗留下的、由终碛垄所包围形成的典型 冰前湖. 枪勇错南北两侧均发育较大规模冰川, 其南部为卡鲁雄峰 (海拔 $6674 \mathrm{~m}$ ), 北部为宁金岗桑峰 (海拔 $7191 \mathrm{~m}$ ), 冰川融水补给的卡鲁雄曲流经枪勇错下游 (图 1c). 枪勇错南北长约 $340 \mathrm{~m}$ 、东西宽约 $280 \mathrm{~m}$, 面积 约 $0.1 \mathrm{~km}^{2}$, 距南部枪勇冰川直线距离约 $1 \mathrm{~km}$, 湖水主要来源于上游枪勇冰川的融水补给 (图 $1 \mathrm{c}, \mathrm{d}$ ). 区域内 分布有多期次的冰碛垄 ${ }^{[24]}$, 基岩以板岩、砂页岩为主,第四纪冰碛物广泛分布于湖区周围. 枪勇冰川发源于 卡鲁雄峰, 属于大陆型冰川, 冰川最大长度约 $5 \mathrm{~km}$, 分布面积约 $7 \mathrm{~km}^{2}$, 冰川末端的海拔约 $5000 \mathrm{~m}^{[25]}$, 冰川融 水除了补给北坡的枪勇错外, 还经下游的卡鲁雄曲向东流人沉错和羊卓雍错. 根据遥感影像显示, 枪勇冰川 北坡的融水几乎全部流人枪勇错,继而经枪勇错流出至卡鲁雄曲.

研究区属于藏南高山谷地高原温带半干旱气候 ${ }^{[26]}$, 在夏季主要受印度季风控制, 冬季则主要受西风带 的影响 ${ }^{[27]}$. 据枪勇错最近的浪卡子县气象站 (海拔 $4470 \mathrm{~m}$ ) 在 1962-2014 年间的资料显示, 当地年均降水 量 $380 \mathrm{~mm}$, 降水主要集中在夏季 $\left(6-8\right.$ 月); 年均温 $3.4^{\circ} \mathrm{C}$, 其中 $7 、 8$ 月平均温度最高 ${ }^{[25,27]}$. 


\section{2 材料与方法}

\section{1 样品采集与测试}

于 2017 年 7 月在枪勇错进行湖泊沉积物岩芯钻取工作, 取得 $105 \mathrm{~cm}$ 长岩芯一支, 编号为 QY5, 钻孔 $\left(28^{\circ} 53^{\prime} 23.65^{\prime \prime} \mathrm{N}, 90^{\circ} 13^{\prime} 33.45^{\prime \prime} \mathrm{E}\right)$ 位于枪勇错上游, 湖泊南部偏东, 水深 $19 \mathrm{~m}$ (图 1d). 整个柱状岩芯岩性以青 灰色黏土质粉砂为主, 样品按 $0.5 \mathrm{~cm}$ 等间距进行分割, 共获取样品 210 个. Zhang 等 ${ }^{[27]}$ 于 2007 年在枪勇错 中心部位取得 QY-3 岩芯一支 (图 1d), 与 QY5 钻孔的直线距离约 $100 \mathrm{~m}$. 下文讨论时用到的 QY-3 数据由中 国科学院青藏高原研究所提供.

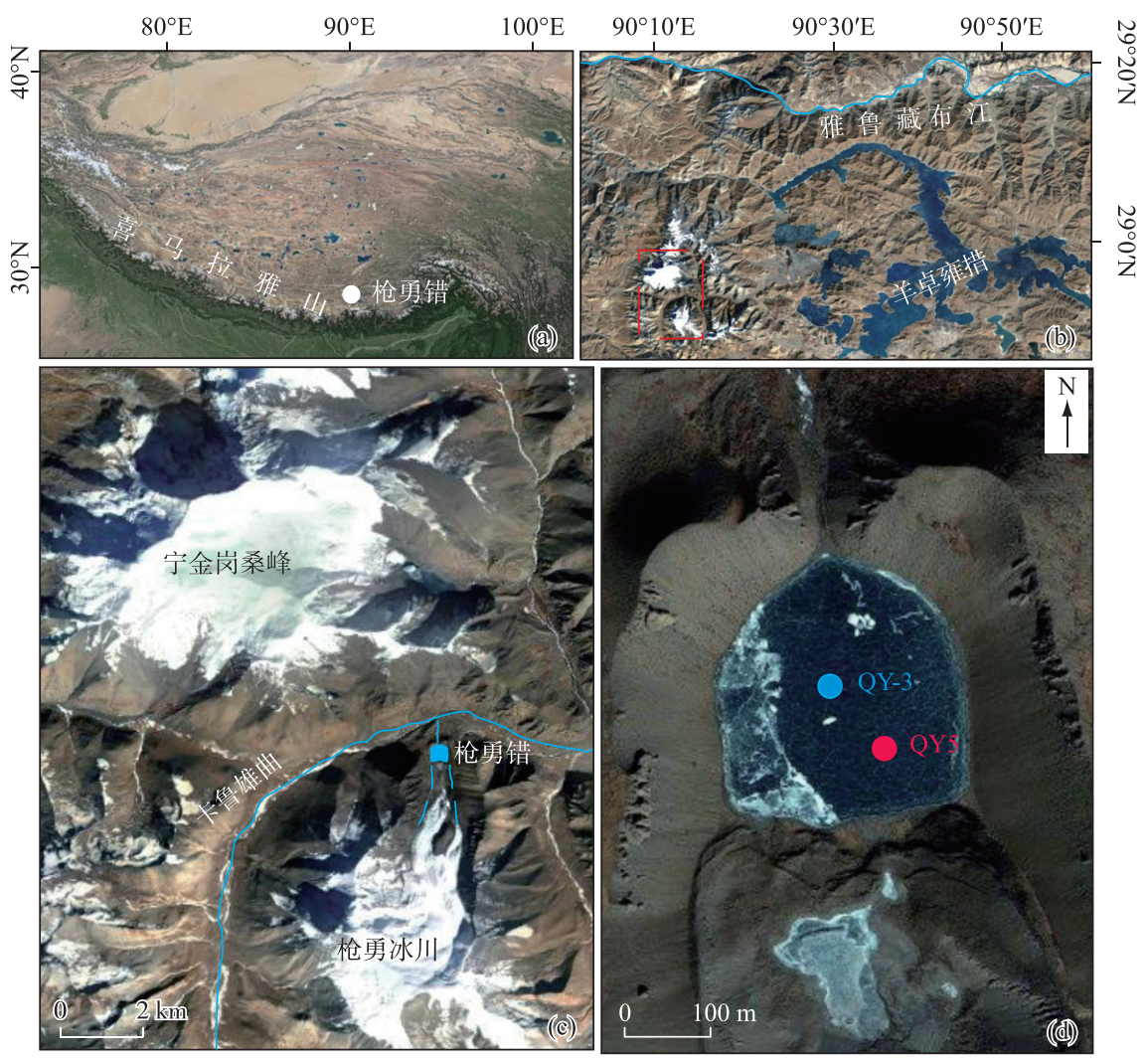

图 1 研究区地理位置 $(\mathrm{a} 、 \mathrm{~b})$ 以及枪勇错、卡鲁雄峰(枪勇冰川) 和宁金岗桑峰分布 $(\mathrm{c})$ 和 湖区遥感图 (d) (图中 QY5 和 QY-3 分别为本研究和文献 [27] 中钻孔的位置)

Fig.1 An overview geographical map of the study area ( $\mathrm{a}, \mathrm{b})$, distribution of Qiangyong Co, Mt. Kaluxung (Qiangyong glacier) and Mt. Noijinkangsang (c), remote sensing imagery of Qiangyong Co catchment (d), with two core sites of QY5 (this study) and QY-3 (from reference [27])

选用 40 个 QY5 样品进行 ${ }^{210} \mathrm{~Pb}$ 和 ${ }^{137} \mathrm{Cs}$ 测试, 以限定枪勇错沉积物年代, 其中前 30 个样品以 $1 \mathrm{~cm}$ 间隔 取样, 第 $31 \sim 35$ 个样品以 $2 \mathrm{~cm}$ 间隔取样, 第 $36 \sim 40$ 个样品以 $5 \mathrm{~cm}$ 间隔取样. ${ }^{210} \mathrm{~Pb}$ 和 ${ }^{137} \mathrm{Cs}$ 测试在中国科学 院南京地理与湖泊研究所湖泊与环境国家重点实验室测试完成. 测试仪器采用美国 ORTEC 公司生产的高 纯锗 $\gamma$ 能谱仪, 其探头型号为 GWL-120-15. 测试流程: 取足量样品烘干, 去除大块有机质, 研磨成粗细均匀 的粉末状, 装人测试样品盒, 密封 10 天, 直接放人探测器井, 测量时间一般按 4 万 8 万秒 (样品计数定). ${ }^{210} \mathrm{~Pb} 、{ }^{137} \mathrm{Cs}$ 和 ${ }^{226} \mathrm{Ra}$ 的标准由中国原子能研究院提供, 通过能谱仪测出总 ${ }^{210} \mathrm{~Pb}$ 比活度, 非补偿 ${ }^{210} \mathrm{~Pb}\left({ }^{210} \mathrm{Pbex}\right)$ 通过总 ${ }^{210} \mathrm{~Pb}$ 扣除 ${ }^{226} \mathrm{Ra}$ 比活度得到. ${ }^{210} \mathrm{~Pb}$ 和 ${ }^{137} \mathrm{Cs}$ 的最低检测限分别为 0.15 和 $0.12 \mathrm{~Bq} / \mathrm{kg}$. 


\section{2 年代限定}

${ }^{137} \mathrm{Cs}$ 作为一种人为产生的放射性核素, 在核试验之后通过大气环流作用散播在全球表层沉积环境中. 1945 年全球首颗原子弹爆炸, 由于全球核试验频发, 1954 年北半球大气中的 ${ }^{137} \mathrm{Cs}$ 含量开始明显上升, 北半 球在 1963 年达到最高值. 1986 年切尔诺贝利核电站泄露事件导致北半球部分地区表层沉积物中的 ${ }^{137} \mathrm{Cs}$ 含 量出现次级蓄积峰值 ${ }^{[28-29]}$, 也有研究认为, 在青藏高原大部分地区不存在明显的 1986 年 ${ }^{137} \mathrm{Cs}$ 蓄积峰, 而只 存在 1963 年的 ${ }^{137} \mathrm{Cs}$ 峰值 ${ }^{[30-33]}$. 因此, 可利用 ${ }^{137} \mathrm{Cs}$ 在沉积物垂向剖面上的最大峰值 (对应 1963 年) 作为沉积 物定年的时间标尺, 1986 年的次级蓄积峰可为部分地区的湖泊沉积物定年提供参考 ${ }^{[28,34-35]}$. 在湖泊沉积过 程中, ${ }^{137} \mathrm{Cs}$ 的分子扩散作用可能导致其垂向分布特征发生变化, 甚至发生上下迁移 ${ }^{[36]}$, 但其蓄积峰的位置 却不会改变,并不影响年龄断代的标志意义 ${ }^{[31,37-38]}$. 本文利用 ${ }^{137} \mathrm{Cs}$ 蓄积峰的位置计算枪勇错沉积物的沉积 速率:

$$
S=D /\left(T_{0}-T_{\mathrm{m}}\right)
$$

式中, $S$ 为平均沉积速率, $\mathrm{cm} / \mathrm{a} ; D$ 为沉积物中 ${ }^{137} \mathrm{Cs}$ 峰值对应的深度, $\mathrm{cm} ; T_{0}$ 为采样年代, $\mathrm{a}$ (本文中为公元 2017 年) ; $T_{\mathrm{m}}$ 为 ${ }^{137} \mathrm{Cs}$ 各个峰值所对应的年代, a.

对 ${ }^{210} \mathrm{~Pb}_{\text {ex }}$ 比活度数据进行处理和计算的方法有 CIC 模式 (constant initial concentration) 和 CRS 模式 (constant rate of supply). CIC 模式适用于 ${ }^{210} \mathrm{~Pb}$ 输人通量与湖泊沉积堆积速率保持恒定的条件,该模式下的湖泊 沉积物主要来自于区域表层物质的侵蚀, ${ }^{210} \mathrm{~Pb}$ 含量受到了陆源碎屑物的影响, 即外界碎屑物输人湖泊的同 时也会导致 ${ }^{210} \mathrm{~Pb}$ 增加 ${ }^{[1,21]}$. CRS 模式适用于 ${ }^{210} \mathrm{~Pb}$ 输人通量不变、沉积堆积速率可能发生改变的条件; 该模 式下的 ${ }^{210} \mathrm{~Pb}$ 主要来自大气沉降, 而流域输人的 ${ }^{210} \mathrm{~Pb}$ 对其总量影响较小 ${ }^{[19,21]}$. 枪勇错沉积物中的 ${ }^{210} \mathrm{~Pb}_{\mathrm{ex}}$ 与质 量深度的指数拟合关系较差 $\left(R^{2}=0.778\right)$, 不同深度的沉积速率会有不同, 因此本文采用 CRS 模式, 再结 合 ${ }^{137} \mathrm{Cs}$ 结果, 来综合限定枪勇错上部沉积物年龄.

\section{3 结果}

\section{$3.1{ }^{137} \mathrm{Cs}$ 定年结果}

根据 ${ }^{137} \mathrm{Cs}$ 分布对比显示, 虽然两个钻孔的位置不同, 但 QY5 的 ${ }^{137} \mathrm{Cs}$ 比活度随岩芯深度变化的模式与 QY-3 的基本一致,两者均存在明显的 1953、1963 和 1986 年 3 个时标 (图 2a), 这说明利用 ${ }^{137} \mathrm{Cs}$ 来对枪勇错 沉积物定年是可信的. QY5 的采样时间为 2017 年, ${ }^{137} \mathrm{Cs}$ 在沉积物中首次出现的时间是在 $15.5 \mathrm{~cm}$ 的 1953 年, 用公式 (1) 得出该段的平均沉积速率为 $0.23 \mathrm{~cm} / \mathrm{a} ; 10.5 \mathrm{~cm}$ 的 ${ }^{137} \mathrm{Cs}$ 比活度达到最大 (对应 1963 年), 该段 沉积速率为 $0.19 \mathrm{~cm} / \mathrm{a}$. 另外, 在 $7.5 \mathrm{~cm}$ 深度检测到的次级蓄积峰可能是 1986 年切尔诺贝利核事故所致, 该 段沉积速率为 $0.23 \mathrm{~cm} / \mathrm{a}$. 在 QY-3 岩芯中 ${ }^{137} \mathrm{Cs}$ 的初始值、最大峰和次级蓄积峰分别出现在 $7.75 、 5.25$ 和 3.25 $\mathrm{cm}^{[26]}$, 对应的平均沉积速率分别为 $0.14 、 0.11$ 和 $0.14 \mathrm{~cm} / \mathrm{a}$. 由此可见, QY5 的沉积速率要比 QY-3 的快两倍 左右. 这是因为 QY-3 位于枪勇错沉积中心, 而 QY5 更靠近河流人湖口, 其沉积速率更大, 即高原冰前湖的 沉积速率在空间上表现出较大差异性. 虽然两根岩芯的沉积速率在数值上表现两倍的差异 (表 1), 但是随 着深度增加两者均呈现 “高一低一高” 的变化趋势, 这可能反映了同一个湖泊不同位置的沉积物来源是一致 的,并且受控于相同的外界动力条件.

\section{$3.2{ }^{210} \mathrm{~Pb}$ 定年结果}

根据 ${ }^{210} \mathrm{~Pb}$ 的 CRS 模式 (图 2b) 得到枪勇错 QY5 岩芯的 ${ }^{210} \mathrm{~Pb}$ 年代偏离了相同层位 ${ }^{137} \mathrm{Cs}$ 峰值所确定的 1963 年. 因此, 下文结合 ${ }^{137} \mathrm{Cs}$ 峰值 (1963 年) 来对 ${ }^{210} \mathrm{~Pb}$ 比活度的定年进行校正, 以此排除由于复杂的外界环 境条件所导致的 ${ }^{210} \mathrm{~Pb}$ 年代偏离. 利用 ${ }^{137} \mathrm{Cs}$ 的峰值, 将沉积物岩芯分为上下两部分, 用不同公式结合 ${ }^{210} \mathrm{~Pb}$ 比 活度来计算这两部分的沉积物年代 ${ }^{[19,39]}$.

${ }^{137} \mathrm{Cs}$ 峰值 (1963 年) 以上的各层位所对应的年代计算公式为:

$$
\begin{aligned}
T_{\mathrm{m}} & =T_{0}+1 / \lambda \ln \left[1+\left(A_{0}-A_{m}\right) \lambda / P\right] \\
P & =\left[-\lambda\left(A_{0}-A_{w}\right)\right] /\left[1-\mathrm{e}^{-\lambda\left(T_{0}-1963\right)}\right]
\end{aligned}
$$

${ }^{137} \mathrm{Cs}$ 峰值 (1963 年) 以下的各层位所对应的年代计算公式为:

$$
T_{m}=1963-1 / \lambda \ln \left(A_{w} / A_{m}\right)
$$


式中, $T_{m}$ 为 $m$ 质量深度所对应的年代; $T_{0}$ 为采样年代; $\lambda$ 为 ${ }^{210} \mathrm{~Pb}$ 衰变常数 $(0.03114) ; A_{0}$ 为整个岩芯 ${ }^{210} \mathrm{~Pb}_{\mathrm{ex}}$ 总 累积量, $\mathrm{Bq} / \mathrm{cm}^{2} ; A_{m}$ 为 $m$ 质量深度以下 ${ }^{210} \mathrm{~Pb}_{\mathrm{ex}}$ 总累积量, $\mathrm{Bq} / \mathrm{cm}^{2} ; A_{w}$ 为 1963 年所对应的 $w$ 层位以下 ${ }^{210} \mathrm{~Pb}_{\mathrm{ex}}$ 总 累积量, $\mathrm{Bq} / \mathrm{cm}^{2}$. 其中, ${ }^{210} \mathrm{~Pb}_{\mathrm{ex}}$ 总累积量 $\left(\mathrm{Bq} / \mathrm{cm}^{2}\right)$ 等于 ${ }^{210} \mathrm{~Pb}$ 活度 $(\mathrm{Bq} / \mathrm{kg})$ 与对应深度样品容重 $\left(\mathrm{g} / \mathrm{cm}^{2}\right)$ 之积 再除以 1000 .

根据公式(2)和 (4) 计算得到枪勇错 QY5 岩芯的年代序列, 校正了 ${ }^{210} \mathrm{~Pb}$ 的年代结果偏离 ${ }^{137} \mathrm{Cs}$ 峰值 (1963 年) 深度, 校正后的 ${ }^{210} \mathrm{~Pb}$ 年代与 ${ }^{137} \mathrm{Cs}$ 的 3 个标志年代 (1953、1963 和 1986 年) 具有更好的拟合效果 (图 2c). 利用 ${ }^{210} \mathrm{~Pb}$ 计算出 $25 \mathrm{~cm}$ 岩芯的沉积速率为 $0.21 \mathrm{~cm} / \mathrm{a}$; 利用 ${ }^{137} \mathrm{Cs}$ 的 3 个标志年代计算出的沉积速 率分别为 $0.23 、 0.19$ 和 $0.23 \mathrm{~cm} / \mathrm{a} ; 1986-1963$ 年和 1963-1953 年这两段的沉积速率变化较大, 分别 0.15 和 $0.45 \mathrm{~cm} / \mathrm{a}$ (表 1). 通过对比 ${ }^{210} \mathrm{~Pb}$ 和 ${ }^{137} \mathrm{Cs}$ 这两种方法计算出的沉积速率, 我们认为校正之后的 ${ }^{210} \mathrm{~Pb}$ 年龄具有 很高的可靠性. 表 1 列出了根据 ${ }^{137} \mathrm{Cs}$ 与 ${ }^{210} \mathrm{~Pb}$ 活度及深度计算出的 QY -3 的沉积速率, 两者的沉积速率在不 同深度/时间段均表现出了相同的变化趋势.
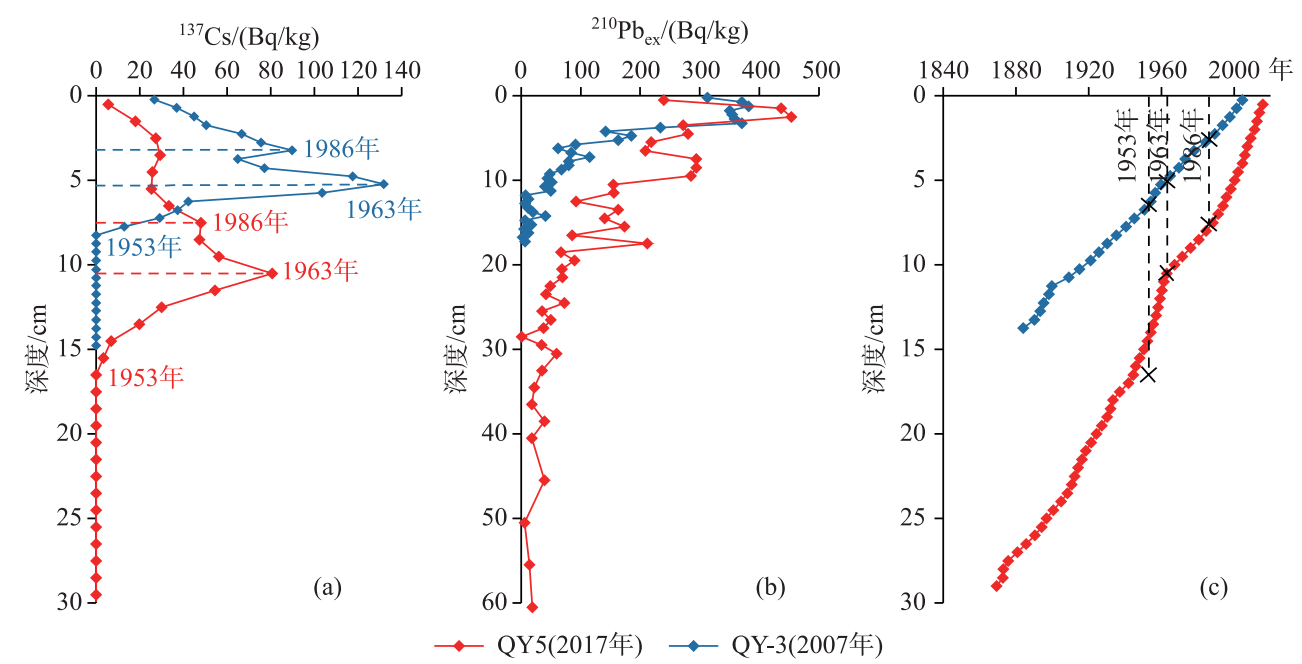

图 2 枪勇错沉积物 ${ }^{137} \mathrm{Cs}(\mathrm{a})$ 和 ${ }^{210} \mathrm{~Pb}_{\text {ex }}$ (b) 比活度变化以及 $\mathrm{QY} 5$ 和 $\mathrm{QY}-3$ 的 ${ }^{210} \mathrm{~Pb}$ 年代模式对比 (c)

Fig.2 Variations of specific activities of ${ }^{137} \mathrm{Cs}$ ( a) and ${ }^{210} \mathrm{~Pb}_{\mathrm{ex}}$ (b) in sediment cores QY5 and QY-3 from Qiangyong Co, and a comparison of ${ }^{210} \mathrm{~Pb}$-based age models between the two cores (c) 表 1 QY5 和 QY-3 的 ${ }^{210} \mathrm{~Pb}$ 和 ${ }^{137} \mathrm{Cs}$ 不同深度平均沉积速率对比 *

Tab.1 Sedimentation rates at different depths of the cores QY5 and QY-3 based on ${ }^{210} \mathrm{~Pb}$ and ${ }^{137} \mathrm{Cs}$ activities

\begin{tabular}{ccccccc}
\hline \multirow{2}{*}{ 方法 } & 时间段 & \multicolumn{2}{c}{ QY5 } & & \multicolumn{2}{c}{ QY-3 } \\
\cline { 3 - 4 } \cline { 5 - 6 } & & 深度/ $\mathrm{cm}$ & 沉积速率 $/(\mathrm{cm} / \mathrm{a})$ & & 深度/ $\mathrm{cm}$ & 沉积速率/ $(\mathrm{cm} / \mathrm{a})$ \\
\hline${ }^{137} \mathrm{Cs}$ & 1986 年 $-T$ & $0 \sim 7.5$ & 0.23 & & $0 \sim 3.25$ & 0.14 \\
${ }^{137} \mathrm{Cs}$ & 1963 年 $-T$ & $0 \sim 10.5$ & 0.19 & & $0 \sim 5.25$ & 0.11 \\
${ }^{137} \mathrm{Cs}$ & 1953 年一 $T$ & $0 \sim 15.5$ & 0.23 & & $0 \sim 7.75$ & 0.14 \\
${ }^{137} \mathrm{Cs}$ & $1963-1986$ 年 & $7.5 \sim 10.5$ & 0.15 & & $3.25 \sim 5.25$ & 0.09 \\
${ }^{137} \mathrm{Cs}$ & $1953-1963$ 年 & $10.5 \sim 15.5$ & 0.45 & & $5.25 \sim 7.25$ & 0.2 \\
${ }^{210} \mathrm{~Pb}$ & 1900 年一 $T$ & 25.0 & 0.21 & & 11.25 & 0.11 \\
\hline
\end{tabular}

* $T$ 为采样时间, QY5 的 $T$ 为 2017 年, QY-3 的 $T$ 为 2007 年. 


\section{4 讨论}

\section{1 枪勇错沉积速率的变化历史}

根据 QY5 的 ${ }^{210} \mathrm{~Pb}$ 年龄计算出岩芯上部 $25 \mathrm{~cm}$ 沉 积物的年代为公元 1900 年, 结合 QY-3 的沉积速率变 化特征, 本文对 1900 年以来沉积速率变化进行讨论 (图 3). 由结果可知, 1900 年以来, QY5 的沉积速率最 小值为 $0.1 \mathrm{~cm} / \mathrm{a}$, 最大值为 $0.54 \mathrm{~cm} / \mathrm{a}$, 平均值为 0.25 $\mathrm{cm} / \mathrm{a}$. QY -3 的沉积速率最小值为 $0.05 \mathrm{~cm} / \mathrm{a}$, 最大值 为 $0.21 \mathrm{~cm} / \mathrm{a}$, 平均值为 $0.11 \mathrm{~cm} / \mathrm{a}$. QY5 的沉积速率为 QY-3 的 2 倍左右,整体变化基本一致,在部分时段表 现出了差异性.

根据图 3 沉积速率的变化趋势, 1900 年以来 QY5 和 QY-3 的沉积速率变化可划分为 3 个阶段:

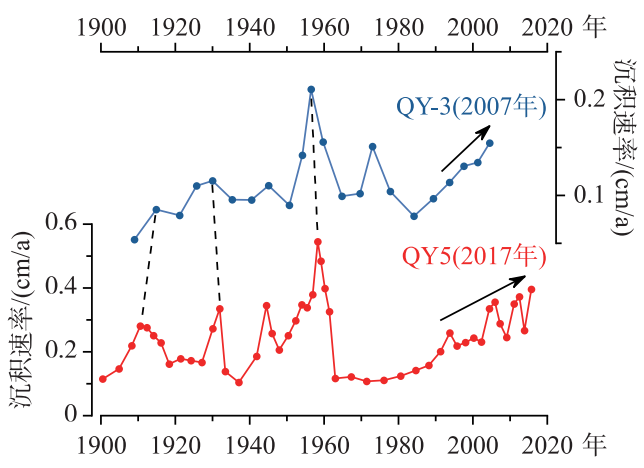

图 3 公元 1900 年以来 QY5 和 QY-3 的沉积速率变化曲线

Fig.3 Correlation of sedimentation rates of the cores QY5 and QY-3 since 1900 A.D. （1）1900-1960 年,两者的沉积速率整体呈上升趋势, 但 QY5 在 1920、1935 和 1950 年前后出现波动, 呈小幅度下降,QY-3 的沉积速率则波动较小, 在 1958 年前后两 者均达到过去百年的最高值. (2) 1960-1985 年, 沉积速率整体低而平稳, QY5 的沉积速率处于整个沉积序列 的最低值, 并保持了 $30 \mathrm{a}$ 左右的稳定值; QY -3 也整体处于低沉积速率状态, 但在 1973 年左右出现一个小峰值. （3）1985 年以来,QY5 的沉积速率在波动中较缓慢地增加;QY-3 则基本处于线性增加的状态 (图 3).

虽然 1900 年以来两个岩芯的沉积速率变化趋势基本一致, 但是处于枪勇错上游 QY5 的沉积速率具有 更加复杂且多变的特征, 特别是第 1 阶段, 表现出了多个峰值, 表明物质来源的快速变化, 而位于湖泊沉积 中心的 QY-3 的沉积速率变化则相对平稳, 这可能是湖泊上游对物源及水动力条件变化反应更加敏感所导 致的. 由此可见, 在以冰川融水补给为主的冰前湖, 靠近冰川的湖泊上游的沉积速率要明显高于湖心或下 游, 且上游的沉积速率对外界环境变化的响应要更加剧烈和明显.

\section{2 冰前湖沉积速率揭示近百年枪勇冰川的波动历史}

作为冰前湖, 化学和生物沉积有限, 其沉积物的来源主要是流域内的松散碎屑物质, 其搬运介质为冰川 融水. 首先, 在冰川融水补给的湖泊中, 由冰川退缩产生冰融水补给湖泊, 不利于碳酸盐等盐类沉淀; 冰川流 域的低温环境也会限制碳酸盐沉淀 ${ }^{[13]}$; 其次, 在寒冷气候条件下, 生物质的量也非常低. 因此,化学和生物 沉积在枪勇错沉积体系中并不占据主要地位. 另外, 枪勇冰川的粉尘积累量仅为 $169 \mu \mathrm{g} /\left(\mathrm{cm}^{2} \cdot \mathrm{a}\right)$, 低于青藏 高原西部及北部地区 ${ }^{[40]}$. 相对于枪勇错上部 $25 \mathrm{~cm}$ 沉积物的最小质量沉积速率 $\left(0.04 \mathrm{~g} /\left(\mathrm{cm}^{2} \cdot \mathrm{a}\right)\right)$, 大气沉 降的粉尘在枪勇错沉积物中所占的比例也可以忽略. 因此,枪勇错的沉积物主要来自冰川磨蚀产生的陆源 碎屑物, 其沉积速率的大小指示了外源碎屑输人通量的变化.

沉积速率是沉积物在单位时间内沉积的厚度, 输人通量越高, 单位时间内沉积的物质就越厚, 而输人通 量则主要受物源及水动力条件 (地表径流量) 的控制. 已有研究表明,在冰川融水补给的地表径流区, 径流与 温度呈正相关, 而悬移质浓度与径流也呈正相关 ${ }^{[41]}$. 在以冰川融水补给为主的卡鲁雄曲, 其径流大小与温 度呈显著正相关, 而降水对径流的控制具有一定程度的不确定性 ${ }^{[42]}$. 因此在该研究区域, 上游补给枪勇错 的地表径流也与冰川融化程度紧密相关, 温度升高, 冰川融化加剧, 径流量和悬移质浓度均增大 (即输人通 量增加，表现为枪勇错内沉积速率增大, 反之亦然.

由此,枪勇错的沉积速率变化可以揭示过去百年枪勇冰川的波动历史 (图 3)：(1) 1900-1960 年, 沉积 速率整体呈增加趋势, 期间出现了几次小幅度的降低, 表明枪勇冰川整体处于后退状态, 有两次短时期的冰 川后退减慢过程 (1920s 和 1930s), 在 1958 年前后枪勇冰川退缩程度可能达到了近百年来的最大. 前人研究 发现, 在 $1940 s-1960 s$ 青藏高原冰川大部分处于退缩状态, 在 $1920 s-1930 s$ 冰川处于相对稳定状态 ${ }^{[43-44]}$; (2) 1960-1985 年,枪勇错沉积速率较低且变化范围较小, 这反映了枪勇冰川维持在相对平稳的状态, 甚至 可能向前扩张. 事实上, 在 1970-1980 年青藏高原大部分冰川处于前进或稳定时期 ${ }^{[43-45]}$. (3) 1985 年以来, 
枪勇错沉积速率波动上升, 该时期冰川后退程度相比于第 2 时段有所增加,但是要弱于第 1 时段,波动幅度 也要比第 1 时段小. 这段时期青藏高原大部分地区的冰川已处于强烈萎缩的状态 ${ }^{[43-46]}$. 由枪勇错沉积速率 揭示的枪勇冰川变化历史与前人在青藏高原的冰川研究具有良好一致性, 这说明了青藏高原大部分地区的 冰川变化在时间上具有很高一致性. 因此, 利用冰前湖沉积物的沉积速率来反演大陆冰川变化也具有有效 性和可靠性.

\section{3 冰川对近百年气候变化的响应}

虽然气候控制着冰川的变化, 但是冰川进退对气候变化却有一定的响应时间, 即冰川变化会出现滞后 效应, 且滞后的程度主要与冰川的规模和物理性质有关. 前人研究表明, 青藏高原的冰川对气候变化的响应 时间大约为 $10 \sim 20 \mathrm{a}^{[43-44,47-48]}$. 事实上, 通过枪勇错沉积速率反演的枪勇冰川进退与气候变化之间也存在有 $5 \sim 10 \mathrm{a}$ 的滞后响应.

通过图 4c 可以看出, 过去百年西藏的温度主要经历了两次升高时期和一次降低时期, 两次变暖时期大 致在公元 1890-1950 年、1980-2000 年, 期间出现了几次小幅度的下降,但总趋势变暖; 一次变冷时期在公 元 1950-1980 年,维持了近 30 a. 将枪勇错沉积速率变化反演的近百年来枪勇冰川的进退变化与西藏温度 的变化对比之后发现,枪勇冰川在近百年来的波动趋势与温度的变化趋势相基本一致,但两者具有 $5 \sim 10 \mathrm{a}$ 左右的滞后时间 (图 4). 两次冰川退缩时期分别发生在 1900-1960 年和 1985 年以来,这两次冰川退缩分别 对应了中国及中国西藏地区温度升高的两个时期 (1890- 1950 年、1980-2000 年); 一次冰川前进时期发生 在公元 1960-1985 年, 这次冰川前进对应于西藏温度降低时期 (1950-1980 年). 其中, 枪勇错沉积速率记 录的 1900-1960 年期间 4 次冰川强烈退缩的时间分别为 1910、1932、1945 和 1958 年, 可各自对应于相对高 温的 1902、1927、1938 和 1948 年, 分别滞后了 $8 、 5 、 7$ 和 $10 \mathrm{a}$ (图 4). 1985 年以来的枪勇错沉积速率也存在几 次小的波动, 但难以与气温进行一一对应, 暗示着该冰川已处于大幅度萎缩的状态. 根据枪勇冰川与温度之 间的对应关系, 冰川变化确实对气候的响应存在一定时间 (5 10 a) 的滞后, 这与前人研究所得出的结论一 致. 因此, 当利用冰前湖沉积指标建立短时间 (年际或年代际) 尺度内冰川活动与气候变化之间的联系时, 应

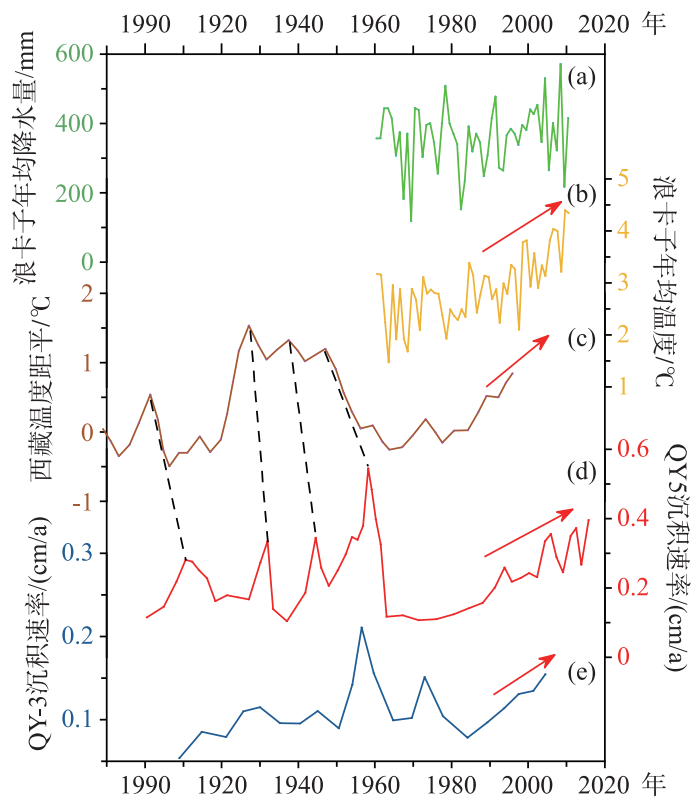

图 4 浪卡子县年均降水量 (a) 和年均温度 (b) (数据引自文献 $[49]$ )、西藏温度距平 (c) (数据引自文献 $[50]) 、 Q Y 5(\mathrm{~d})$ 及 QY-3(e) 的沉积速率对比

Fig.4 Correlation of annual average precipitation (a) and temperature (b) in Langkazi County

(from reference $[49]$ ), temperature anomalies in Tibet (c) (from reference $[50]$ ), the sedimentation rates of the cores QY5 (d) and QY-3 (e) 
当注意冰川变化对气候变化的滞后效应,否则可能会出现冰川变化指标与气候变化不一致的现象.

枪勇冰川对温度变化响应具有 5 10 a 的滞后, 我们进一步对比了 1970-2017 年期间枪勇错沉积速率 与 1960-2010 年期间浪卡子气象站的年均温度和年均降水量资料 ${ }^{[49]}$ (图 4) 之后发现, 沉积速率与温度同 步变化,均表现出上升的趋势; 而与年均降水量之间并没有呈现同步变化. 事实上,浪卡子气象站所记录的 降水量在 1960-2010 年间基本保持不变. 由此可见,在短时间尺度内沉积速率所揭示的枪勇冰川进退变化 主要受控于温度,降水量对该地区冰川变化的影响较小.

全球气候变暖仍在持续, 并有可能进一步加剧. Yao 等利用器测数据研究发现, 喜马拉雅地区冰川快速 退缩已是不争的事实 ${ }^{[9]}$. 总的来说, 近百年来枪勇冰川的退缩主要受到气候变暖的影响,枪勇错沉积速率所 指示的冰川变化与中国和中国西藏地区的温度变化有着良好对应关系. 即使冰川对气候变化响应存在滞后 效应, 在未来几十年内,枪勇冰川的融化速率可能会继续上升. 我们认为, 在未来全球气候变暖的背景之下, 枪勇流域甚至是整个喜马拉雅地区可能会面临着冰川融化加剧的巨大威胁, 势必对亚洲水塔造成直接的 影响.

\section{5 结论}

本文依据 ${ }^{210} \mathrm{~Pb}$ 和 ${ }^{137} \mathrm{Cs}$ 数据限定了藏南冰前湖枪勇错沉积物年龄, 用 ${ }^{137} \mathrm{Cs}$ 峰值 (1963 年) 对 ${ }^{210} \mathrm{~Pb}$ 年龄进 行校正,计算出 QY5 岩芯的平均沉积速率为 $0.21 \mathrm{~cm} / \mathrm{a}$, 约是湖泊中心 QY-3 岩芯的 2 倍, 但两个岩芯的沉积 速率具有相同的变化趋势. 靠近人湖口的 QY5 的沉积速率记录了更为精细的冰川变化特征, 是湖泊上游对 物源及水动力等外界环境条件变化响应更敏感的反映.

通过 QY5 的沉积速率揭示了过去百年枪勇冰川经历 3 个阶段: (1) 公元 1900-1960 年,沉积速率整体 呈增加趋势, 枪勇冰川处于快速退缩的阶段; (2) 公元 1960-1985 年, 枪勇错沉积速率较低且变化较小, 反 映了枪勇冰川的变化维持在相对平稳的水平, 甚至可能向前扩张; (3) 公元 1985 年以来, 枪勇错沉积速率整 体上升,该时期的冰川融化有所增加，但退缩强度和波动幅度均小于第 1 阶段.

枪勇错沉积速率所反演的近百年来枪勇冰川退缩和前进的时期分别对应温度上升和下降的时期, 温度 是影响枪勇冰川变化的主要控制因素, 但两者之间还存在 5 10 a 的滞后效应. 由于全球变暖持续和冰川对 气候响应的滞后效应,未来几十年内枪勇冰川融化速率可能会有所加快.

致谢: 感谢中国地质科学院水文地质环境地质研究所万的军副研究员和中国科学院南京地理与湖泊研究所 夏威岗高级工程师在年代测试和分析方面给予的指导和帮助。

\section{6 参考文献}

[ 1 ] Peng YJ, Xiao JL, Nakamura T et al. Holocene East Asian monsoonal precipitation pattern revealed by grain-size distribution of core sediments of Daihai Lake in Inner Mongolia of north-central China. Earth and Planetary Science Letters, 2005 , $233(3 / 4)$ : 467-479. DOI: 10.1016/j.epsl.2005.02.022.

[ 2 ] Liu XQ, Dong HL, Yang XD et al. Late Holocene forcing of the Asian winter and summer monsoon as evidenced by proxy records from the northern Qinghai-Tibetan Plateau. Earth and Planetary Science Letters, 2009, 280(1/2/3/4) : 276-284. DOI: $10.1016 /$ j.epsl.2009.01.041.

[ 3 ] An ZS, Colman SM, Zhou WJ et al. Interplay between the Westerlies and Asian monsoon recorded in Lake Qinghai sediments since 32 ka. Scientific Reports, 2012, 2: 619. DOI: 10.1038/srep00619.

[ 4 ] Hakanson L, Jansson M eds. Translated by Zheng GY. Principles of lake sedimentology. Beijing: Science Press, 1992: 1193. [霍坎松, 杨松. 郑光膺译. 湖泊沉积学原理. 北京: 科学出版社, 1992: 1-193.]

[ 5 ] Zhao SZ, Kong FJ, Wang XK et al. ${ }^{210} \mathrm{~Pb}$ and ${ }^{137} \mathrm{Cs}$ dating and modern sedimentation rate on the Wuliangsu Lake of Inner Mongolia. Geoscience, 2008, 22(6) : 909-914. [ 赵锁志, 孔凡吉, 王喜宽等. 内蒙古乌梁素海 ${ }^{210} \mathrm{~Pb}$ 和 ${ }^{137} \mathrm{Cs}$ 测年与现 代沉积速率. 现代地质, 2008, 22(6): 909-914.]

[ 6] Wang YH, Shen HT. The study methods of sedimentation rates in the estuarine and coastal environments. Marine Geology \& Quaternary Geology, 2002, 22(2) : 115-120. [王永红, 沈焕庭. 河口海岸环境沉积速率研究方法. 海洋地质与第 四纪地质, 2002, 22(2) : 115-120.] 
[ 7 ] Mann ME, Jones PD. Global surface temperatures over the past two millennia. Geophysical Research Letters, 2003,30 (15) : 1820. DOI: 10.1029/2003GL017814.

[ 8 ] Change IC. Contribution of working groups I , II and III to the fourth assessment report of the intergovernmental panel on climate change. 2007.

[ 9 ] Yao TD, Thompson L, Yang W et al. Different glacier status with atmospheric circulations in Tibetan Plateau and surroundings. Nature Climate Change, 2012, 2(9): 663-667. DOI: 10.1038/nclimate1580.

[10] Yao TD, Li ZG, Yang W et al. Glacial distribution and mass balance in the Yarlung Zangbo River and its influence on lakes. Chinese Science Bulletin, 2010, 55(18) : 1750-1756. DOI: 10.1007/s11434-010-3213-5. [姚檀栋, 李治国, 杨 威等. 雅鲁藏布江流域冰川分布和物质平衡特征及其对湖泊的影响. 科学通报, 2010, 55(18): 1750-1756.]

[11] Stansell ND, Rodbell DT, Abbott MB et al. Proglacial lake sediment records of Holocene climate change in the western Cordillera of Peru. Quaternary Science Reviews, 2013, 70: 1-14. DOI: 10.1016/j.quascirev.2013.03.003.

[12] Stansell ND, Polissar PJ, Abbott MB et al. Proglacial lake sediment records reveal Holocene climate changes in the Venezuelan Andes. Quaternary Science Reviews, 2014, 89: 44-55. DOI: 10.1016/j.quascirev.2014.01.021.

[13] Liu XQ, Herzschuh U, Wang YB et al. Glacier fluctuations of Muztagh Ata and temperature changes during the late Holocene in westernmost Tibetan Plateau, based on glaciolacustrine sediment records. Geophysical Research Letters, 2014,41 (17) : 6265-6273. DOI: 10.1002/2014GL060444.

[14] Huang L, Zhu LP, Wang JB et al. Glacial activity reflected in a continuous lacustrine record since the early Holocene from the proglacial Laigu Lake on the southeastern Tibetan Plateau. Palaeogeography, Palaeoclimatology, Palaeoecology, 2016, 456: 37-45. DOI: 10.1016/j.palaeo.2016.05.019.

[15] de Wet GA, Balascio NL, D'Andrea WJ et al. Holocene glacier activity reconstructed from proglacial lake Gjøavatnet on Amsterdamøya, NW Svalbard. Quaternary Science Reviews, 2018, 183: 188-203. DOI: 10.1016/j.quascirev.2017.03.018.

[16] Sutherland JL, Carrivick JL, Shulmeister J et al. Ice-contact proglacial lakes associated with the last glacial maximum across the southern Alps, New Zealand. Quaternary Science Reviews, 2019, 213: 67-92. DOI: 10.1016/j.quascirev.2019. 03.035 .

[17] Xu T, Zhu LP, Lü X et al. Mid- to late-Holocene paleoenvironmental changes and glacier fluctuations reconstructed from the sediments of proglacial lake Buruo Co, northern Tibetan Plateau. Palaeogeography, Palaeoclimatology, Palaeoecology, 2019, 517: 74-85. DOI: 10.1016/j.palaeo.2018.12.023.

[18] Xia WL, Xue B. The ${ }^{210} \mathrm{~Pb}$ and ${ }^{137} \mathrm{Cs}$ chronological measurement on sedimentation rate of Xiaolongwan, Jilin. Quaternary Sciences, 2004, 24(1) : 124-125. [夏威岗, 薛滨. 吉林小龙湾沉积速率的 ${ }^{210} \mathrm{~Pb}$ 和 ${ }^{137} \mathrm{Cs}$ 年代学方法测定. 第四纪研 究, 2004, 24(1): 124-125.]

[19] Liu EF, Xue B, Yang XD et al. ${ }^{137} \mathrm{Cs}$ and ${ }^{210} \mathrm{~Pb}$ chronology for modern lake sediment: a case study of Chaohu Lake and Taibai Lake. Marine Geology \& Quaternary Geology, 2009, 29(6) : 89-94. DOI: 10.3724/SP.J.1140.2009.06089. [刘恩 峰, 薛滨, 羊向东等. 基于 ${ }^{210} \mathrm{~Pb}$ 与 ${ }^{137} \mathrm{Cs}$ 分布的近代沉积物定年方法一以巢湖、太白湖为例. 海洋地质与第四纪 地质, 2009, 29(6): 89-94.]

[20] Jin AC, Jiang QF, Chen Y et al. ${ }^{210} \mathrm{~Pb}$ and ${ }^{137} \mathrm{Cs}$ dating and modern sedimentation rate in the Wulungu Lake, Xinjiang. Geoscience, 2010, 24(2) : 377-382. [ 金爱春, 蒋庆丰, 陈晔等. 新疆乌伦古湖的 ${ }^{210} \mathrm{~Pb} 、{ }^{137} \mathrm{Cs}$ 测年与现代沉积速率. 现代地质, 2010, 24(2): 377-382.]

[21] Chai SL, Gao LN, Qiu DM et al. ${ }^{210} \mathrm{~Pb}$ and ${ }^{137} \mathrm{Cs}$ dating of the sediment core and its recent accumulation rates in Yueliang Lake in west Jilin Province. Journal of Jilin University: Earth Science Edition, 2013, 43(1): 134-141. [柴社立, 高丽 娜, 邱殿明等. 吉林省西部月亮湖沉积物的 ${ }^{210} \mathrm{~Pb}$ 和 ${ }^{137} \mathrm{Cs}$ 测年及沉积速率. 吉林大学学报: 地球科学版, 2013, 43 (1) : 134-141.]

[22] Wan DJ, Song L, Yang JS et al. Increasing heavy metals in the background atmosphere of central North China since the 1980s: Evidence from a 200-year lake sediment record. Atmospheric Environment, 2016, 138: 183-190. DOI: 10.1016/j. atmosenv.2016.05.015.

[23] Wan DJ, Mao X, Jin ZD et al. Sedimentary biogeochemical record in Lake Gonghai: Implications for recent lake changes in relatively remote areas of China. Science of the Total Environment, 2019, 649: 929-937. DOI: 10.1016/j. scitotenv. 2018.08.331.

[24] Owen LA, Finkel RC, Barnard PL et al. Climatic and topographic controls on the style and timing of Late Quaternary glaci- 
ation throughout Tibet and the Himalaya defined by ${ }^{10} \mathrm{Be}$ cosmogenic radionuclide surface exposure dating. Quaternary Science Reviews, 2005, 24(12/13) : 1391-1411.

[25] Liu JH, Yi CL, Li YK. Reconstruction of the neoglacial glacier in the Qiangyong valley, Mt. Kaluxung, south Tibet. Quaternary Sciences, 2018, 38(2) : 348-354. [刘金花, 易朝路, 李英奎. 藏南卡鲁雄峰枪勇冰川新冰期冰川发育探讨. 第四纪研究, 2018, 38(2) : 348-354.]

[26] Zheng JY, Yin YH, Li BY. A new scheme for climate regionalization in China. Acta Geographica Sinica, 2010, 65(1): 3-12. [郑景云, 尹云鹤, 李炳元. 中国气候区划新方案. 地理学报, 2010, 65(1): 3-12.]

[27] Zhang JF, Xu BQ, Turner F et al. Long-term glacier melt fluctuations over the past $2500 \mathrm{yr}$ in monsoonal High Asia revealed by radiocarbon-dated lacustrine pollen concentrates. Geology, 2017, 45(4) : 359-362. DOI: 10.1130/g38690.1.

[28] Chu GQ, Gu ZY, Xu B et al. Varve chronology and radiometric dating $\left({ }^{137} \mathrm{Cs},{ }^{210} \mathrm{~Pb}\right)$ from the Sihailongwan Maar, northeastern China. Quaternary Sciences, 2005, 25(2): 202-207. [储国强, 顾兆炎, 许冰等. 东北四海龙湾玛珥湖沉积物 纹层计年与 ${ }^{137} \mathrm{Cs},{ }^{210} \mathrm{~Pb}$ 测年. 第四纪研究, 2005, 25(2): 202-207.]

[29] Lu HY, Cao JJ, Han YM et al. History of heavy elements in the last 250 years recorded by sediments in Huguang maar lake (Huguangyan). Marine Geology \& Quaternary Geology, 2010, 30(1) : 47-53. [鲁海燕, 曹军䩀, 韩永明等. 湖光 岩玛珥湖沉积记录的近 250 年重金属元素污染历史. 海洋地质与第四纪地质, 2010, 30(1) : 47-53.]

[30 ] Zeng L, Wu FC, Wan GJ et al. The distribution characteristic and environmental significance of Cesium-137 deposit profile in Chinese lacustrine sediment. J Lake Sci, 2009, 21 (1) : 1-9. DOI: 10.18307/2009.0101. [曾理, 吴丰昌, 万国江等. 中国地区湖泊沉积物中 ${ }^{137} \mathrm{Cs}$ 分布特征和环境意义. 湖泊科学, 2009, 21(1): 1-9.]

[31] Zhang XB, Long Y, Wen $\mathrm{AB}$ et al. Discussion on applying ${ }^{137} \mathrm{Cs}$ and ${ }^{210} \mathrm{~Pb}_{\mathrm{ex}}$ for lake sediment dating in China. Quaternary Sciences, 2012, 32(3) : 430-440. [张信宝, 龙翼, 文安邦等. 中国湖泊沉积物 ${ }^{137} \mathrm{Cs}$ 和 ${ }^{210} \mathrm{~Pb}_{\mathrm{ex}}$ 断代的一些问题. 第四 纪研究, 2012, 32(3) : 430-440.]

[32] Ma XZ, Wang YB, Zhao CC et al. Modern sedimentary process of Lake Basomtso in the southeastern Tibetan Plateau and its response to climate change. J Lake Sci, 2019, 31(4) : 1169-1181. DOI: 10.18307/2019.0403. [马学志, 王永波, 赵辰辰等. 青藏高原东南部巴松措现代沉积过程及其对气候变化的响应. 湖泊科学, 2019, 31(4): 1169-1181.]

[33 Lan JH, Wang TL, Chawchai S et al. Time marker of ${ }^{137}$ Cs fallout maximum in lake sediments of Northwest China. Quaternary Science Reviews, 2020, 241: 106413.

[34] Xiang L. Limitations of the application of ${ }^{137} \mathrm{Cs}$ limnochronology : a case study of ${ }^{137} \mathrm{Cs}$ profile in Craward lake sediment. $J$ Lake Sci , 1995, 7 (4) : 307-313. DOI: 10.18307/1995.0403. [ 项亮. ${ }^{137} \mathrm{Cs}$ 湖泊沉积年代学方法应用的局限一一 Crawford 湖为例. 湖泊科学, $1995,7(4): 307-313$. ]

[35] Wieland E, Santschi PH, Höener P et al. Scavenging of Chernobyl ${ }^{137} \mathrm{Cs}$ and natural ${ }^{210} \mathrm{~Pb}$ in Lake Sempach, Switzerland. Geochimica et Cosmochimica Acta, 1993, 57(13) : 2959-2979.

[36] You HT, Liu Q, Liu JQ et al. A comparative study on model sedimentation rates with varve dating, ${ }^{137} \mathrm{Cs}$ and ${ }^{210} \mathrm{~Pb}$ dating in Erlongwan maar lake, NE China. Journal of Jilin University: Earth Science Edition, 2007, 37(1) : 59-64. [ 游海涛, 刘强, 刘嘉鹿等. 纹层计年与 ${ }^{137} \mathrm{Cs} 、{ }^{210} \mathrm{~Pb}$ 法对比研究东北二龙湾玛珥湖现代沉积速率. 吉林大学学报: 地球科学 版, 2007, 37(1): 59-64.]

[37] Wang GJ. Progresses on ${ }^{137} \mathrm{Cs}$ and ${ }^{210} \mathrm{~Pb}_{\mathrm{ex}}$ dating of lake sediments. Advance in Earth Sciences, 1995, 10(2): 188-192. [万国江. ${ }^{137} \mathrm{Cs}$ 及 ${ }^{210} \mathrm{~Pb}_{\mathrm{ex}}$ 方法湖泊沉积计年研究新进展. 地球科学进展, 1995, 10(2): 188-192.]

[38] Wan GJ. ${ }^{210} \mathrm{~Pb}$ dating for recent sedimentation. Quaternary Sciences, 1997, 17(3): 230-239. [万国江. 现代沉积的 ${ }^{210} \mathrm{~Pb}$ 计年. 第四纪研究, 1997, 17(3): 230-239.]

[39] Last WM, Smol JP eds. Tracking environmental change using lake sediments, volume 1: Basin analysis, coring, and chronological techniques. Dordrecht: Kluwer Academic Publishers, 2001: 171-196.

[40] Wake CP, Mayewski PA, Li Z et al. Modern eolian dust deposition in central Asia. Tellus B: Chemical and Physical Meteorology, 1994, 46(3) : 220-233. DOI: 10.3402/tellusb.v46i3.15793.

[41] Pu HZ, Han TD, Ding YJ et al. The changing features of total dissolved solids and suspended sediment in the Dongkemadi Glacier catchment, Tanggula Mountains. Journal of Glaciology and Geocryology, 2018, 40(5): 993-1003. [蒲红铮, 韩 添丁, 丁永建等. 唐古拉山冬克玛底冰川流域河水总溶解固体和悬移质的变化特征. 冰川冻土, 2018, 40 (5): 993-1003.] 
[42] Zhang F, Liu JS, Gong TL et al. Hydrological regime of the Karuxung watershed in north Himalayas. Acta Geographica Sin$i c a, 2006,61(11):$ 1141-1148. [张菲, 刘景时, 巩同梁等. 喜马拉雅山北坡卡鲁雄曲径流与气候变化. 地理学报, 2006, 61(11): 1141-1148.

[43] Su Z, Liu ZX, Wang WT et al. Glacier fluctuations responding to climate change and forecast of its tendency over the Qinghai Tibet plateau. Advance in Earth Sciences, 1999, 14(6): 607-612. [苏珍, 刘宗香, 王文悌等. 青藏高原冰川 对气候变化的响应及趋势预测. 地球科学进展, 1999, 14(6): 607-612.]

[44] Duan JP, Wang LL, Ren JW et al. Progress in glacier variations in China and its sensitivity to climatic change during the past century. Progress in Geography, 2009, 28(2): 231-237. [段建平, 王丽丽, 任贾文等. 近百年来中国冰川变化及 其对气候变化的敏感性研究进展. 地理科学进展, 2009, 28(2) : 31-237.]

[45] Yao TD, Liu SY, Pu JZ et al. Impact of the recently glacier retreat on water resources in High Asia. Science in China: Series D, 2004, 34(6) : 535-543. [姚檀栋, 刘时银, 蒲健辰等. 高亚洲冰川的近期退缩及其对西北水资源的影响. 中 国科学: D 辑: 地球科学, 2004, 34(6): 535-543.]

[46] Ren JW, Qin DH, Jing ZF. Climatic warming causes the glacier retreat in Mt. Qomolangma. Journal of Glaciology and Geocryology, 1998, 20(2) : 184-185. [任贾文, 秦大河, 井哲帆.气候变暖使珠穆朗玛峰地区冰川处于退缩状态. 冰川冻土, $1998, \mathbf{2 0}(2):$ 184-185.]

[47] Ren JW, Qin DH, Kang SC et al. Characteristics of glaciers change and warm-dry climate in the middle Himalayas region. Chinese Science Bulletin, 2003, 48(23) : 2478-2482. [任贾文, 秦大河, 康世昌等. 喜马拉雅山中段冰川变化及气候 暖干化特征. 科学通报, 2003, 48(23): 2478-2482.]

[48] Pu JC, Yao TD, Wang NL et al. Fluctuations of the glaciers on the Qinghai-Tibetan Plateau during the past century. Journal of Glaciology and Geocryology, 2004, 26(5) : 517-522. [蒲健辰, 姚檀栋, 王宁练等. 近百年来青藏高原冰川的 进退变化. 冰川冻土, 2004, 26(5): 517-522.]

[49] Dan ZCJ, Zhuo M, Dan ZWD et al. Analysis of the characteristics of temperature and precipitation in the region of Karuola glacier in the near 50a. Climate Change Research Letters, 2018, 7(3): 199-203. [旦增措杰, 卓玛, 旦增旺堆等. 卡若 拉冰川区域近 50a 年气温、降水变化特征分析.气候变化研究快报, 2018, 7(3) : 199-203.]

[50] Wang SW, Ye JL, Gong DY et al. Construction of mean annual temperature series for the last one hundred years in China. Quarterly Journal of Applied Meteorlolgy, 1998, 9(4): 9-18. [王绍武, 叶瑾琳, 龚道溢等. 近百年中国年气温序列的 建立. 应用气象学报, 1998, 9(4): 9-18.] 